\title{
Whistleblower rewards, false reports, and corporate fraud
}

\author{
Paolo Buccirossi ${ }^{1}$. Giovanni Immordino ${ }^{2}$ (iD . Giancarlo Spagnolo ${ }^{3}$
}

Accepted: 12 April 2021 / Published online: 29 April 2021

(C) The Author(s) 2021

\begin{abstract}
It is often claimed that rewards for whistleblowers lead to fraudulent reports, but for several US programs this has not been a major problem. We model the interaction between rewards for whistleblowers, sanctions against fraudulent reporting, judicial errors, and standards of proof in the court case on a whistleblower's allegations and the possible follow-up for fraudulent allegations. Balancing whistleblower rewards, sanctions against fraudulent reports, and courts' standards of proof is essential for these policies to succeed. When the risk of retaliation is severe, larger rewards are needed and so are tougher sanctions against fraudulent reports. The precision of the legal system must be sufficiently high, hence these programs are not viable in weak institution environments, where protection is imperfect and court precision low, or where sanctions against false reporting are mild.
\end{abstract}

Keywords Whistleblowers rewards · False allegations $\cdot$ Judicial errors · Standard of proof $\cdot$ Corporate fraud

JEL codes $\mathrm{G} 38 \cdot \mathrm{K} 20 \cdot \mathrm{K} 42 \cdot \mathrm{L} 40 \cdot \mathrm{M} 41$

Giovanni Immordino

giovanni.immordino@unina.it

Paolo Buccirossi

paolo.buccirossi@learlab.com

Giancarlo Spagnolo

spagnologianca@gmail.com

1 LEAR, Rome, Italy

2 Università di Napoli Federico II and CSEF, Naples, Italy

3 EIEF, Tor Vergata, CEPR, SITE-Stockholm School of Economics, Stockholm, Sweden 


\section{Introduction}

Discovering crimes by eliciting already existing information from witnesses or accomplices may be-at least in some circumstances-more effective than searching for new information through costly investigations. This is why most legal regimes in history have had implicit or explicit forms of incentives for whistleblowers. However, explicit and structured financial incentives for whistleblowers, while increasingly popular in the US, are viewed with skepticism in Europe (see Nyreröd \& Spagnolo, 2021). ${ }^{1}$ Disagreement in the policy debate touches many aspects, but one argument frequently put forward by opponents of such schemes is that they are rendered ineffective by the many false reports that a prospect of a reward will prompt. ${ }^{2}$ This, however, does not seem to have been a major issue in the US, where the agencies administering some of these schemes argue that they are game-changers that dramatically increase detection rates. ${ }^{3}$ Indeed, the long and successful US experience with the False Claim Act demonstrates that the potential problems engendered by the risk of false reports can be addressed. The risk that high-powered incentives lead to many fabricated accusations can be controlled directly through more severe sanctions against defamation, perjury and information fabrication. ${ }^{4}$ It could also be controlled by the adoption of a stricter standard of proof by courts that evaluates information coming from witnesses who stand to gain from a conviction, an effect that may offset the reward-driven incentive to forge information, at the cost of a lower conviction

\footnotetext{
1 While an informed critical attitude is always useful, the origin of some of the skepticism from European regulatory authorities is less clear. For example, in 2014 the Bank of England's Prudential Regulation Authority and the Financial Conduct Authority wrote a joint Note (BoE-PRA and FCA 2014) for the UK parliament offering widespread but rather unsubstantiated criticism of financial incentives to whistleblowers, neglecting all the empirical evidence available from the US experience (see again Nyreröd \& Spagnolo, 2021).

${ }^{2}$ For example, Howse and Daniels report that "it is often claimed that the prospect of large awards to whistleblowers provides an incentive for employees to fabricate claims of wrongdoing for personal profit." (1995, p.540). According to a recent report by Transparency International, "Employers' representatives have been reluctant to publicly welcome the bill and have claimed it may open them to reputational damage and false or malicious claims." (2013, p. 54). A report by the law firm DLA Piper (2015) on whistleblowing also stresses the risk of "malicious or unfounded allegations" against employers. Analogous concerns are expressed in the above-mentioned 2014 note by the Bank of England.

3 For example, in her speech at the Garret Institute in April 2015, Mary Jo White, the SEC Chairman, argued with respect to the SEC's whistleblower awards program, established by the Dodd-Frank Act in 2010, that: "The program, while clearly still developing, has proven to be a game-changer." According to the SEC, many hints and successful enforcement actions have already been linked to the whistleblower reward program.

4 Some suggest that this is indeed how this problem is avoided in the US, although additional provisions may be needed in other institutional settings. For example, Amanda Rose (2014) writes: "While it is unlikely that the WBP will produce many tips that are outright fabrications (the requirement that whistleblowers submit their tips under penalty of perjury, as well as the requirement that the SEC bring a covered action based on the tip before a bounty may be awarded, seems a sufficient guard against this), the lure of a large bounty could motivate individuals to view honest conduct as suspicious." (2014. p. 1283)
} 
rate. ${ }^{5}$ Alternatively, it could be controlled by lowering or capping the rewards for whistleblowers. Moreover, the accuracy of the legal system is likely to play an important role. The interesting question is how to combine these tools to design an effective program.

In this paper we tackle this question. We develop a model that focuses on the interaction between financial rewards for whistleblowers, sanctions for reporting false/fabricated information (perjury, defamation), judicial errors, and standards of proof in two court cases: one based on a whistleblower's allegations and a potentially consequent one against a whistleblower accused of fraudulent reporting false/fabricated information. We use the model first to shed light on the tradeoffs involved and to characterize an effective whistleblower program, i.e. a program that minimizes the occurrence of illegal behavior.

Our results show that to design an effective reward program it is crucial to find an appropriate balance between the reward offered to successful whistleblowers and the sanctions against those convicted for knowingly reporting false information. Given other parameters, a balanced ratio between these two parameters is the crucial tool that can lead to an effective program, suggesting that sufficiently severe sanctions against whistleblowers convicted of forging information are necessary in order to compensate for large rewards.

When taking into account retaliation from employers and the fact that protection from retaliation is necessarily incomplete (not all forms of retaliation can be observed by a court), we show that there is a minimum size of the reward, below which whistleblowing will not take place at all, independent of the ratio mentioned above. In these cases, the reward must substantially exceed the sanction imposed on a mendacious whistleblower the more so the larger the risk that a firm will retaliate and the weaker the whistleblower protection.

The choice of the standard of proof is also crucial. Given the level of accuracy, an overly strict standard of proof, with very few false positives and therefore many false negatives, induces potential whistleblowers to never report and the firm to always commit wrongdoing. Similarly, when the standard of proof is too low, the many false positives induce potential whistleblowers to always blow the whistle, whether or not the firm is guilty, again leading to more illegal acts. The standard of proof must therefore be chosen with due care to avoid turning these schemes into failures.

Improving courts' accuracy — which reduces both types of error-is the only policy with unambiguously positive effects in terms of relaxing the constraints for a

\footnotetext{
5 The expectation of a sizable tightening of the standard of proof applied by courts when hearing testimonies from financially rewarded whistleblowers appears to be one reason why officials in the Antitrust Division of the Department of Justice (the institution that works so effectively with the False Claim Act) recently opposed a proposal to introduce a whistleblower reward program in antitrust (see, e.g. GAO 2011). This is a somewhat strange concern for the case of cartels, because these involve many firms and several individuals in each firm. Rewards could be awarded to one (innocent) informed individual who reports a cartel, only to detect new cartels. Then many other individuals, such as the leniency applicants that are not rewarded, can continue testifying in court, as is the case today. This concern may make sense, instead, for frauds and other crimes where there are not as many other non-rewarded individuals that could be called to witness.
} 
whistleblower reward scheme to be effective. From a short-run perspective (in which the level of accuracy of the judiciary cannot be modified), our results imply that whistleblowing reward schemes are useful instruments only when the court system is sufficiently precise, and that they are not likely to perform as one would hope in environments with weak institution, where court precision is low.

The rest of the paper unfolds as follows. In Sect. 2 we discuss the related literature. Section 3 presents the baseline model and Sect. 4 the related results. Section 5 considers two separate and potentially different trials: one where the firm is judged for illegal behavior, and another where the employee is judged for filing a false case. Section 6 briefly concludes.

\section{Related literature}

Informal discussions on the costs and benefits of rewarding whistleblowers financially abound but despite the relevance of the issue and the lively policy debate, with extremely divided views across the Atlantic, there has been little formal economic analysis. ${ }^{6}$ The first formal economic analyses of rewards programs are those on accomplice-witness whistleblowers. Spagnolo (2004) and Aubert et al. (2006) emphasize the significant additional deterrence effects these schemes may bring about, arguing strongly for their introduction, but also highlighting their possible adverse effects when ill-designed, on firms' behavior, turnover, the incentives for innovation and cooperation, and how to minimize them. Friebel and Guriev (2012) study rewards for innocent whistleblowers on accounting management (e.g. overstatement of financial results) highlighting that besides deterring such unlawful behavior they may also have negative effects on firms' productive efficiency by limiting the ability to give managers high powered incentives. Felli and Hortala-Vallve (2016) show how whistleblower rewards can be used as a tool to prevent collusion or blackmail on the part of members of a hierarchical structure. Piccolo and Immordino (2016) study leniency programs against organized crime and find that when a boss can design complex internal rules that reward his agents based on the quality of the information they can disclose, the legislator must rely on rewards to induce agents to report information. The most recent theoretical analysis, and the closest to our paper, is Givati (2016). It studies whistleblower rewards in a stylized model where reporting employees bears an exogenous personal cost, and where the reward generates an exogenous risk of false reports. It finds a non-monotonic relationship between the size of the personal cost and the optimal reward, so that if the cost is too large, a reward should not be offered, and the crime should not be deterred. An analogous non-monotonic relationship is found between the exogenous risk of a

\footnotetext{
6 The costs and benefits of rewarding whistleblowers have been discussed informally in, for example, Howse and Daniels (1995). A highly influential article in the Washington Post by Zingales (2004) argued strongly in favor of rewarding whistleblowers who uncover financial fraud, as is currently happening at the SEC. Kovacic (2000) argued in favor of introducing these schemes in antitrust. There is an extensive legal literature on whistleblower rewards, recently surveyed in Engstrom (2016).
} 
false report and the size of the reward, such that if the risk of a false report is too large, no reward should be offered to avoid false reports. It also shows that when the exogenous risk of a false report is small, whistleblowing dominates policing as a law enforcement strategy.

The model of Givati (2016) does not consider what happens after a whistleblower loses the case and is sued by the employer for fraudulent reporting. That is instead the core part of our model that allows us to endogenize the incentive for false reports created by rewards, and to show how it can be counterbalanced by appropriate sanctions against fraudulent reporting (for defamation in reality), offering an explanation for the very few cases of fraudulent reports observed within whistleblower reward programs in the US (Nyreröd \& Spagnolo, 2021). The analysis of the complete game also allows us to characterize the subtle role played by the standard of proof and the importance of courts' accuracy for the effectiveness of a whistleblower reward program. ${ }^{7}$

On the empirical side

The first 'classic' systematic empirical study of reward programs for whistleblowers is Dyck et al. (2010). The authors investigate empirically who blows the whistle on corporate fraud by assembling and analyzing data on all reported fraud cases in large U.S. companies between 1996 and 2004. They find that in sectors where whistleblower rewards are available through the False Claim Act, like the health industry, fraud is uncovered thanks to employees blowing the whistle in $41 \%$ of cases. This percentage falls to $14 \%$ in industries in which whistleblower's rewards are not available, a high statistically significant difference.

A number of empirical studies and reports from US agencies followed this paper, confirming the ability of whistleblower rewards to substantially increase detection and deterrence of corporate wrongdoing and to bring in the tax-payer's coffer multiples of their administrative costs, with little problems of false reporting. Nyreröd and Spagnolo (2021) survey these studies in detail. Here, we mention a few more recent studies that are not included in this survey.

Amir et al. (2018) explore the effects of the introduction of a whistleblower hotline and reward program in Israel in February 2013. The introduction of the policy was concurrent with a large media campaign attracting attention to the hotline with the intention to boost the awareness and therefore the deterrence effects of the

\footnotetext{
7 Somewhat less related is Heyes and Kapur (2009), examining theoretically how regulators should respond to whistleblowers' tip-offs, but assume that monetary rewards are not present and focus on alternative psychological theories of why they blow the whistle in the absence of financial incentives to do it.

Mechtenberg et al. (2017) study the possibility that even whistleblower protection is abused by low productivity employees to postpone termination by filing fraudulent claims, suggesting that it may be efficient to let protection only start after the court has judged on the whistleblower's claim. It assumes, however, that judicial proceedings are instantaneous, so that firms cannot retaliate against whistleblowers while the court case is ongoing (many years in many countries); and that whistleblowers cannot be punished for filing fraudulent claims (although innocent firms will have a significant probability of winning in court against them, and all the resources and incentives-disciplining other employees-to pursue fraudulent whistleblowers as harshly as possible). We conjecture that in their model more realistic assumptions would lead to different results and policy prescriptions.
} 
program. They found a significant increase in tax collections after the hotline was introduced in sectors where there is a high risk of tax avoidance.

Wiedman and Zhu (2018) study the deterrent effects of Dodd-Frank's whistleblower provisions by examining their impact on aggressive financial reporting in US firms. They measure aggressive reporting using the absolute value of abnormal accruals, and find a significant reduction in abnormal accruals (approximately 11\%) following the introduction of Dodd-Frank's whistleblower rewards program. They also show that reductions in aggressive reporting are greater for firms with weaker internal reporting programs where employees are more likely to blow the whistle directly at the SEC, as internal reporting is less likely to take place.

Raleigh (2020) tests the effectiveness of Dodd-Frank's whistleblower provisions on reducing insider trading by corporate insiders-a form of violation widely regarded to be more difficult to detect than corporate-level fraud. He finds that for a sample of firms that lobbied against Dodd-Frank's whistleblower provisions, the profitability of insider purchases is significantly reduced post Dodd-Frank relative to the profitability of other insiders. Similar results are obtained for insiders within firms with weak internal whistleblower programs, who are more likely to be sensitive to the new regulation, and for other analyses of insider transactions. The broader finding is that whistleblowers are an effective deterrent of insider trading, and a highly valuable resource for uncovering this hard-to-detect illegal activity.

Lastly, a particularly thorough study by Leder-Luis (2020) empirically measures the costs and benefits of whistleblower rewards under the False Claim Act. The empirical analysis pairs whistleblower filings and allegations with large samples of Medicare claims data from 1999-2016, allowing to measure the benefits in terms of specific deterrence of selected whistleblower cases, the public costs of whistleblowing, and its effects on patient health. To measure deterrence effects, he conducts several case studies of large settled whistleblower lawsuits and analyzes their effects on Medicare claims and spending. The results suggest that, for the four case studies, the specific deterrence value of whistleblower cases exceeded $\$ 18$ billion in the first 5 years. This figure ignores the potentially very large additional benefits in terms of general deterrence. Of course, efficiency considerations also need to consider costs, such as expenditures by federal agencies overseeing and contributing to litigation, and private costs of attorneys. He uses federal budget data reports and estimates that total public spending for the whistleblower program was a mere $\$ 108.5$ million in 2018 , confirming that whistleblower rewards have an enormous return on investment for the taxpayer, even disregarding their general deterrence effects.

\section{On the experimental side}

The difficulties linked to the measurement of undetected illegal behavior make this field one where laboratory experiments can be a very useful complement. Studies on rewards for innocent whistleblowers, i.e. bystanders or employees not involved with the crime, focused more on their motivation than on their effects on crime. For example, Breuer (2013) studies the effects of rewards for whistleblowers in a laboratory experiment on tax evasion and finds a strong positive effect on subjects' willingness to blow the whistle, little sign of crowding out of non-monetary motivation, and a significant fall in tax evasion. Stikeleather (2016) runs an experiment framed as a corporate theft scenario and finds a significant increase in the rate 
of internal whistleblowing when monetary rewards are granted. Schmolke and Utikal (2016) study the frequency of whistleblowing generated by rewards, fines for not blowing the whistle, as well as whether, and how, the enforcing authority is affected by the whistleblower's report. Butler et al. (2017) study the interaction between monetary rewards, the visibility of the crime reported, and public image concerns of the whistleblowers. Most relevant for us, both studies find that, controlling for other factors, monetary rewards are very effective in increasing the probability of whistleblowing.

A second strand of the experimental literature on whistleblower rewards looks at situations where one of the parties of a potential or actual illegal transaction/relationship is offered amnesty (if the illegal action occurred) and a monetary reward for blowing the whistle and reporting the illegal transaction/relationship to law enforcers. The focus of this literature is on the effects of offering a reward to whistleblowers on crime deterrence. For example, Apesteguia et al. (2007) study rewards for whistleblowers in an experiment on illegal cartel formation and find that whistleblower bonuses do not reduce market prices relative to the "no incentives" treatment, although they produce the highest likelihood of whistleblowing. In a repeated game version of an analogous leniency experiment where subjects had more occasions to experiment and learn the subtleties of the strategic environment, Bigoni et al. (2012) find that rewards for blowing the whistle (funded through the fines paid by others) led to very high reporting rates and rapidly to full collusion deterrence, as predicted by the theory developed in Spagnolo (2004). A strong effect of whistleblower rewards on the deterrence of illegal transactions is also found in a recent lab experiment on bribery by Abbink and Wu (2017). There, the possibility for one party to obtain amnesty and a (modest) monetary reward when blowing the whistle has a strong deterrence effect on isolated illegal transactions, although the effect of repeated relationships is more limited (but still positive).

Beyond economics, there is an extensive literature on whistleblowing in the areas of law, sociology, psychology, business, and public administration that we cannot cover here (see surveys in Engstrom 2016; Miceli \& Near, 1992; Miceli, et al., 2008).

\section{The baseline model}

Consider a simple game between a firm that chooses whether to act legally or illegally, and an employee who, after observing the firm's choice, can decide to file a case against the firm or to remain silent.

Undetected illegal behavior yields a random monetary return $\pi$, distributed on the support $(0,+\infty)$ with cumulative distribution function $H(\pi)$ and probability density function $h(\pi)$. If the employee blows the whistle (either against a guilty firm or against an innocent firm), a trial takes place without loss of generality with probability 1 and may end up with a right or a wrong verdict. Let 0 be the normalized profits of the honest firm that is not convicted and the payoff of the employee when he does not file a case, $F$ the monetary sanction faced by a convicted firm, $R$ the reward the employee gets in case of a successful filing, and $f$ the sanction imposed 
on an employee who is convicted of fabricating information. Whistleblowers are subject to various forms of retaliation, many of which cannot be covered by whistleblower protection laws where these are present (for instance, slowing down career progression, delayed promotions, or blacklisting/lack of offers from other firms in the industry). We address this issue explicitly by introducing the possibility of retaliation measured by a parameter $P$, the punishment a whistleblower is subject to when the reported entity retaliates. ${ }^{8}$

Two errors may occur at the end of the trial: a false positive and a false negative. We indicate with $\alpha_{p}$ the probability of wrongful conviction of an innocent firm (false positive) induced by the standard of proof prescribed to courts for this situation by the current legal system; and with $\alpha_{n}$ the probability of wrongful acquittal of a guilty firm (false negative) under the same system. Following the contributions by Kaplow (2011a, b, 2012) we shall also assume $\alpha_{n}^{\prime}\left(\alpha_{p}\right)<0$ and $\alpha_{i} \in[0, \bar{\alpha}]$ with $\bar{\alpha}<\frac{1}{2}$ and $i=p, n$. Note that setting the probability of conviction of an innocent firm $\alpha_{p}$ automatically determines the probability of acquittal of a guilty firm $\alpha_{n}\left(\alpha_{p}\right)$. This assumption captures the idea that it is not possible to reduce type 1 error without increasing type 2 error, holding overall accuracy constant. ${ }^{9}$

We also assume that the employee gets the reward $R$ if the firm is convicted, and the sanction $f$ if the firm is acquitted. Therefore $\alpha_{p}$ also represents the probability that the reward is paid to an employee who files a false claim, and $\alpha_{n}\left(\alpha_{p}\right)$ represents the probability that the employee is sanctioned when he files against a guilty firm.

The timing of the baseline game is as follows:

$\mathrm{t}=1$ The return from undetected illegal behavior $\pi$ materializes. The firm decides whether to commit the illegal act or not. Once the illegal act is committed, the game proceeds to the next stage.

$\mathrm{t}=2$ The employee, knowing if an illegal act has been committed or not, decides whether to file a claim (false or otherwise).

$\mathrm{t}=3$ The trial uncertainty resolves and sanctions are imposed.

The solution concept is subgame perfect Nash equilibrium.

All players are risk-neutral, so that sanctions can be interpreted as the monetary equivalent of the imprisonment terms, fines, damages, and so forth, to which the criminals expose themselves. We also assume the following tie-breaking condition.

\footnotetext{
8 This parameter can also be interpreted as the inverse of the degree of whistleblower protection allowed by a legal system, with $P=0$ being the (unlikely) case of perfect protection from retaliation.

${ }^{9}$ Let us clarify how Kaplow (2011a) formally specifies the relationship between $\alpha_{p}$ and $\alpha_{n}$. He assumes that there is a set of evidence produced when an agent (a firm) is scrutinized. This evidence is represented by a variable $x$, a signal of the underlying act. The densities and cumulative distribution functions for $x$ are given by $g_{j}(x)$, assumed to be positive, and $G_{j}(x)$, where $j=I, \varnothing$ refers to a firm that has committed an illegal act or none respectively. Suppose that the evidence threshold is set at some $\hat{x}$, meaning that sanction $F$ is applied if and only if the value of the signal $x$ exceeds $\hat{x}$. Since $G_{j}(\hat{x})$ denotes the probability that the signal falls below the threshold, it follows that $\alpha_{n}(\hat{x})=G_{I}(\hat{x})$ while $\alpha_{p}(\hat{x})=1-G_{\varnothing}(\hat{x})$. Inverting the function $\alpha_{p}(\hat{x})$ implies a value of $\hat{x}$ and hence of $\alpha_{n}(\hat{x})$. Accordingly, we can also define an implicit function for $\alpha_{n}$ that will be denoted $\alpha_{n}\left(\alpha_{p}\right)$. Finally, using the definitions of $\alpha_{i}$ we have $\alpha_{n}^{\prime}\left(\alpha_{p}\right)=\frac{d \alpha_{n}}{d \alpha_{p}}=\left[d \alpha_{n} / d \hat{x}\right] /\left[d \alpha_{p} / d \hat{x}\right]=-\left[g_{I}(\hat{x}) / g_{\varnothing}(\hat{x})\right]$ which is negative.
} 
A1 When the employee is indifferent between blowing the whistle and remaining loyal to the firm, he chooses the latter option.

For the purposes of this paper, a whistleblower program is described by a quadruple $\left(R, f, \alpha_{p}, P\right)$. In what follows, we will take all of these items and the monetary sanction $F$ as given, and focus on the equilibrium behavior of firms (choosing to engage in illegal activity or not) and potential whistleblowers (choosing to allege illegal activity or not). We then characterize the set of these instruments that makes the program effective, i.e. that minimizes the occurrence of illegal activity, referred to as the crime rate.

\section{The benchmark}

In order to solve the model, suppose that (along the equilibrium path) the firm has committed an illegal act. Then, the employee will file a case if and only if

$$
u_{I}=\left(1-\alpha_{n}\left(\alpha_{p}\right)\right) R-\alpha_{n}\left(\alpha_{p}\right) f-P>0 \Leftrightarrow \frac{\left(1-\alpha_{n}\left(\alpha_{p}\right)\right)}{\alpha_{n}\left(\alpha_{p}\right)}>G,
$$

where $G \equiv \frac{f+P}{R-P}$. If, instead the firm has not committed an illegal act, then the employee will file a false claim if and only if

$$
u_{L}=\alpha_{p} R-\left(1-\alpha_{p}\right) f-P>0 \Leftrightarrow \frac{\alpha_{p}}{1-\alpha_{p}}>G,
$$

where $u_{I}$ and $u_{L}$ are the employee's expected utility in each subgame. Note that

$$
S_{I} \equiv \frac{\left(1-\alpha_{n}\left(\alpha_{p}\right)\right)}{\alpha_{n}\left(\alpha_{p}\right)} \text { and } S_{L} \equiv \frac{\alpha_{p}}{1-\alpha_{p}}
$$

are the odds of success, defined as the ratio of the probability of success over the probability of failure, from filing a case with and without merit, respectively. Moreover, $S_{I}>1>S_{L}$ because $\alpha_{i}<\frac{1}{2}$. Then, depending on the design of the whistleblower program $\left(R, f, \alpha_{p}, P\right)$ there are only three possible cases. In the first case, the employee always blows the whistle (this is the case if $S_{I}>S_{L}>G$ ). In the second case the employee blows the whistle only when the firm misbehaved (i.e. $S_{I}>G \geqslant S_{L}$ ). Finally, the employee never blows the whistle if $G \geqslant S_{I}>S_{L}$.

Going backward, we now characterize the firm's decision to commit an illegal act. The firm's profit from committing an illegal act is $\pi$ if the employee does not blow the whistle and $\pi-F\left(1-\alpha_{n}\left(\alpha_{p}\right)\right)$ otherwise. Instead, profits from behaving legally are 0 if the employee does not blow the whistle and $-F \alpha_{p}$ otherwise. Next, note that if $S_{I}>S_{L}>G$, the employee always blows the whistle, and the firm decides to act illegally or not by comparing $\pi-F\left(1-\alpha_{n}\left(\alpha_{p}\right)\right)$ and $-F \alpha_{p}$. In this case, the crime is committed if and only if the return exceeds the following threshold 


$$
\underline{\pi} \equiv F\left(1-\alpha_{n}\left(\alpha_{p}\right)-\alpha_{p}\right)
$$

which is increasing in the firm's sanction $F$ and in the probability of conviction of an innocent firm $\left(\alpha_{p}\right)$ whenever increasing false positives decreases false negatives more than proportionally $\left(\alpha_{n}^{\prime}\left(\alpha_{p}\right)<-1\right) .{ }^{10}$ If instead $S_{I}>G \geqslant S_{L}$, the employee blows the whistle only when the firm misbehaves and the firm decides to act illegally or not by comparing 0 and $\pi-F\left(1-\alpha_{n}\left(\alpha_{p}\right)\right)$. In this second case, the crime is committed if and only if the return on the crime exceeds the following threshold

$$
\bar{\pi} \equiv F\left(1-\alpha_{n}\left(\alpha_{p}\right)\right)
$$

which is increasing in the firm's sanction $F$ and in the probability of conviction of an innocent firm $\alpha_{p}$. Finally, if the employee never blows the whistle $\left(G \geqslant S_{I}>S_{L}\right)$, the firm will always commit the illegal act since $\pi>0$. Putting together our findings above, we get a complete characterization of the (subgame perfect) equilibrium of our model and the chracterization of an effective program.

Proposition 1 If $S_{I}>S_{L}>G$, the employee always blows the whistle and the crime rate is

$$
\operatorname{Pr}[\pi \geqslant \underline{\pi}]=1-H\left(F\left(1-\alpha_{n}\left(\alpha_{p}\right)-\alpha_{p}\right)\right),
$$

which is decreasing in the firm's sanction $F$ and in the probability of conviction of an innocent firm $\alpha_{p}$ whenever $\alpha_{n}^{\prime}\left(\alpha_{p}\right)<-1{ }^{11}$

If $S_{I}>G \geqslant S_{L}$, the employee blows the whistle only when the firm misbehaves and the crime rate is

$$
\operatorname{Pr}[\pi \geqslant \bar{\pi}]=1-H\left(F\left(1-\alpha_{n}\left(\alpha_{p}\right)\right)\right),
$$

which is decreasing in the firm's sanction $F$ and in the probability of conviction of an innocent firm $\alpha_{p}{ }^{12}$

Finally, if $G \geqslant S_{I}>S_{L}$, the employee never blows the whistle and the crime rate is 1 .

Hence, the program is effective if and only if $S_{I}>G \geqslant S_{L}$.

\footnotetext{
${ }^{10}$ Clearly, when $\alpha_{n}^{\prime}\left(\alpha_{p}\right) \geqslant-1$, increasing false positives will decrease false negatives less than proportionally resulting in a decrease of $\underline{\pi}$.

11 When $\alpha_{n}^{\prime}\left(\alpha_{p}\right) \geqslant-1$, increasing false positives will increase the crime rate.

12 Since, for simplicity, we are assuming that firms will only be prosecuted if a whistleblower reports incriminating information/files a claim against them, in the specific cases we will of course have $\alpha_{p}^{i}=0$ when in situation $i$ the whistleblowers never file claims against innocent firms, and $\alpha_{n}^{j}=1$ when in situation $j$ whistleblowers never file claims against a guilty firm either. The comparative statics on the error probabilities is possible because it is on the legal system's parameters $\alpha_{p}\left(\alpha_{n}\right)$, not on the probability in each specific case.
} 
Recall that $S_{I}$ and $S_{L}$ are the odds of success, defined as the ratio of the probability of success over the probability of failure, from filing a case with and without merit, respectively. Then, the area where the probability of successfully filing a case is larger than $G$-both following legal and illegal behavior by the firmrepresents whistleblower programs that induce an employee to file a case against all firms including honest ones. In this area the firm decides to misbehave (or not) depending on the sanction $F$ and on the errors which may occur at the end of the trial. The area where the probability of successfully filing a case is larger than $G$ following illegal behaviors-but is smaller for legal ones-represents whistleblower programs such that employees denounce guilty firms and the firm behaves legally when the firm's sanction $F$ and the probability of conviction of an innocent firm $\alpha_{p}$ are sufficiently high. Finally, if the probability of successfully filing a case is always smaller than $G$, the program never provides an incentive to file a case, so that the firm always acts illegally.

A few comments are in order. For the sake of simplicity, consider first the case in which the firm is not allowed to retaliate against whistleblowers i.e. $P=0$, so that $G=f / R$.

First, it is clear that rewards for honest whistleblowers and sanctions against dishonest ones must be strictly related. The danger of fixing the wrong combination of these two policy parameters is disrupting the entire program. In the case that the incentive structure of the program is such that the employee always acts against the firm, and even more so in the opposite case, firms may as well act illegally, counting on a defective policing and judiciary system.

Second, for very low values of $f$, the range of rewards, $R$, that lead to an effective program is very narrow, but it gets larger and larger as long as $f$ increases. A corollary of proposition 1 is that (if $P=0$ ) a sufficient condition to be in case 2 , is to set $R=f$. One would think that when the reward is a percentage of a firm's illicit gain plus monetary fines, as in some actual programs, then a monetary sanction for a mendacious whistleblower, which is constrained by his personal wealth, may be insufficient to balance the incentives. Then, a high-powered bounty program could call for criminal sanctions against a whistleblower that files a fraudulent claim. On the other hand, our model is stylized and should be properly interpreted: accounting for standard decreasing marginal value of money and loss aversion a monetary fine much smaller than the reward can be sufficient to balance incentives.

Third, notice that $S_{I}$ and $S_{L}$ depend on $\alpha_{p}$ and $\alpha_{n}$. Therefore, the accuracy of the legal system and the standard of proof are important policy instruments

Standard of proof. The choice of the burden of proof that has to be met to convict a firm is extremely important to make the program work. To see this, consider that increasing the standard of proof will decrease $\alpha_{p}$ and increase $\alpha_{n}$. This choice would determine a lower value for both $S_{I}$ and $S_{L}$, making it less likely that the employee files a case. In other words, an imperfect setting of the burden of proof could change the program from one where employees always blow the whistle to one where they never do (or vice versa), missing the area in which the program is effective. 
We have also to bear in mind that the burden of proof is on the plaintiff and thus, to some extent, on the whistleblower. Therefore, if the standard of proof is increased, the whistleblower will bear higher costs to successfully apply to the program as she has to provide evidence with a stronger probative value. This may be implicitly captured in our model by considering $R$ as the reward net of all the costs the whistleblower bears. Hence, an increase in the standard of proof implies both a lower value for both $S_{I}$ and $S_{L}$ and a lower value of $R$. This strengthens our previous conclusion.

Accuracy. Even if whistleblower programs are seen as a mechanism to elicit information that would not be available otherwise, courts must not rely only on information provided by relators. Whistleblowers programs have to be seen as complements to other interventions that improve the accuracy of the judiciary system. As explained by Kaplow (2011b), accuracy determines the overall error rate of the legal system, whereas the burden of proof dictates how to divide the errors between the two types. This also shows that a whistleblower program may prove very dangerous if it is introduced in countries where, due to corruption or to an inefficient system, the performance of courts is unsatisfactory. Indeed, investments made to improve the accuracy of the system will decrease the probability of one type of error (e.g. $\alpha_{p}$ ) without increaing the probability of the other error type (e.g. $\alpha_{n}$ ) and, possibly, decrease the probability of both types of error. This will make $S_{I}$ and $S_{L}$ move apart $\left(S_{I}\right.$ increases and $S_{L}$ decreases), increasing the probability that the whistleblower program is effective.

Let us now summarize, by way of a thought experiment, why the accuracy of the legal system and the standard of proof are important dimensions to take into account. Assume that $S_{I}>S_{L}>f / R$ and that the $f / R$ cannot be modified. Then, we are in the area where the employee always blows the whistle. Suppose that we can only change the burden of proof to switch to the first-best scenario where $S_{I}>f / R \geqslant S_{L}$ so that the employee blows the whistle only when the firm misbehaves. Imagine now a reduction in the probability of conviction of an innocent firm $\alpha_{p}$, then $S_{L}$ will decrease going in the right direction. However, decreasing the probability of a false positive will increase the possibility of a false negative, so that $S_{I}$ will also decrease. Therefore, depending on the relative speed at which $S_{L}$ and $S_{I}$ decrease, we might enter the worst-case scenario, i.e. $f / R \geqslant S_{I}>S_{L}$, where the employee never blows the whistle and the crime rate is maximal. However, this worst-case scenario could be avoided by improving accuracy — for instance by decreasing $\alpha_{p}$ without increasing $\alpha_{n}\left(\alpha_{p}\right)$ - so that the change in the burden of proof is counterbalanced by an overall improvement in the judicial system. It is interesting to note that making courts' decisions more accurate may have different impacts depending on whether the investments lead to a reduction in the probability of false negatives or in the probability of false positives. This can be shown graphically.

Figures 1 and 2 describe the impact of improving the accuracy of the judiciary on the effectiveness of the whistleblower program. Figure 1 assumes that the probability of a false negative remains the same, so that $S_{I}$ remains constant, and shows how $S_{L}$ changes as we improve the judicial system and lowers the probability of false positives. Since the whistleblower program is effective if $G$ lies between $S_{I}$ and $S_{L}$, the distance between the two curves identifies the range of values that $G$ can take for an effective program. This distance increases as the accuracy of courts 


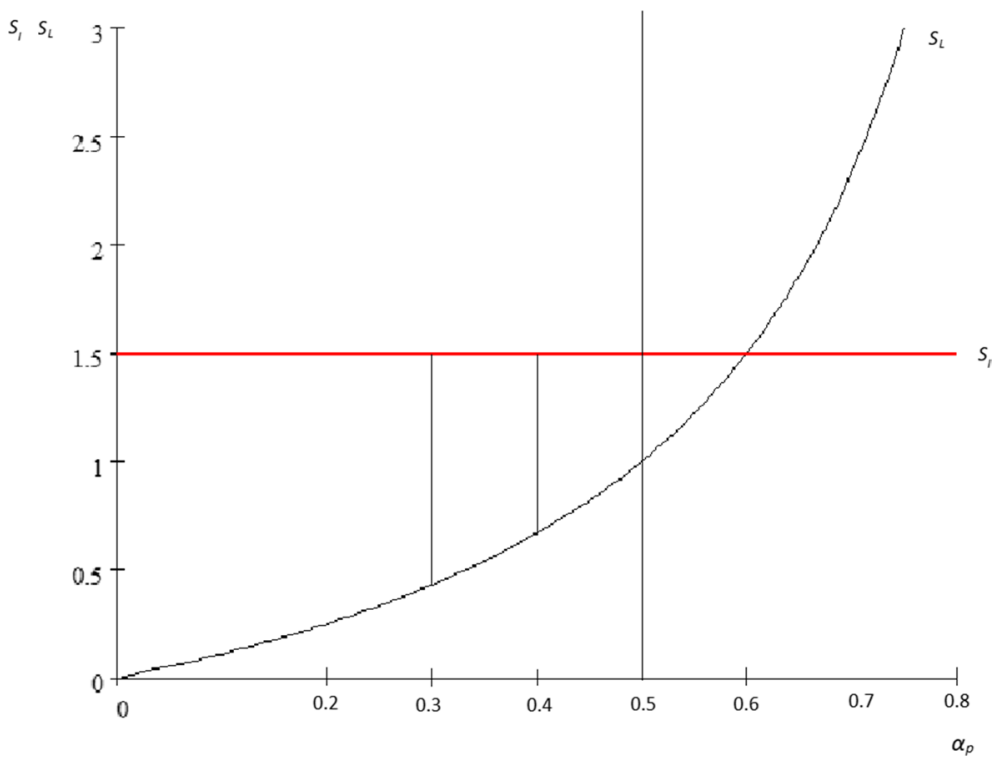

Fig. 1 Effect of a decrease in the probability of false positives

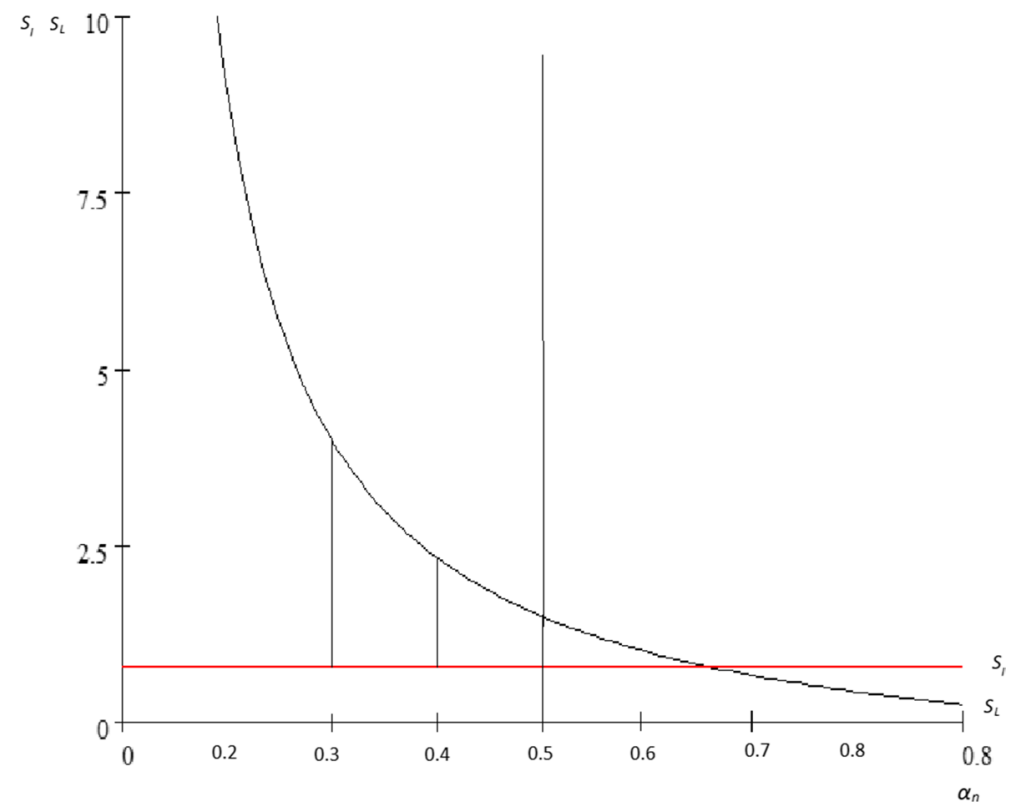

Fig. 2 Effect of a decrease in the probability of false negatives

improves. In the diagram, we depict the distance between $S_{I}$ and $S_{L}$ when $\alpha_{p}$ is 0.4 and when $\alpha_{p}$ is 0.3 . The figure also shows that the marginal return of a reduction 
in the probability of false positives is decreasing, so that this policy intervention becomes progressively less relevant.

Figure 2 depicts the effect of investments in the judicial system that leads to a decrease in the probability of false negatives, keeping the probability of false positives constant. Again, the distance between the two curves identifies the range of values in which $G$ must fall to have an effective program. This range increases as courts become more accurate as shown in the figure, for $\alpha_{n}$ equal to 0.4 and 0.3 . However, in this case the marginal return of lowering the probability of false negatives is increasing and the policy intervention becomes progressively more effective. Of course, this is not enough to conclude that any investment should aim at improving the accuracy of courts so that the occurrence of false negatives decreases, as we do not know if the relative cost of achieving a lower probability of false negatives is high or low compared to the cost of improving the accuracy of the system in relation to false positives.

Consider now the case in which $P>0$. Although most of our previous remarks are still valid, there is one important difference. In the previous discussion, we argued that the rewards for honest whistleblowers and the sanctions against dishonest ones need to be balanced. The absolute value of rewards for filing a merit case $R$ and the sanction for filing one without merit $f$ were not determinative, but the ratio between the two was crucial. This result is due to the lack of any personal costs from blowing the whistle for the employee. More realistically, we now observe that there will never be reporting if the reward $R$ is not sufficiently larger than the expected punishment $P$, since otherwise the employee's expected utility from filing a case will always be negative. Indeed, the sufficient condition that guarantees an effective program requires a combination of reward and sanction such that $G=1$. However, this entails $R=f+2 P$, so that, if $P>0$, the reward must exceed the sanction imposed on a mendacious whistleblower, the more so the larger is the risk that a firm will retaliate against the relator whenever turned in and whenever the protection provided to whistleblowers is weak. This result proves that the whistleblower legislation that has been enacted in many European countries, whose limited purpose is to protect whistleblowers from retaliatory measures, is inadequate and cannot lead to an effective program.

\section{Criminal versus administrative trial}

Until now, we have assumed that there is only one trial where either the firm is convicted for illegal behavior, or the employee is convicted for filing a false case (e.g. fabricating information). In reality, of course, there would be two separate processes, and there is the possibility that neither the firm nor the employee is convicted. Complicating the model by considering the two separate and potentially different trials does not dramatically affect our previous conclusions, but it allows us to study how different combinations of efficiency/precision of the legal system in the two trials affect the performance of whistleblower schemes. 
As before, let 0 be the profits of the honest firm that is not convicted and the payoff of the employee when he does not file a case, $\pi$ the profits of undetected illegal behavior, $F$ the monetary sanction faced by a convicted firm, and $R$ the reward the employee gets in case of a successful filing, net of any personal costs. Again, two errors may occur at the end of a trial: a false positive and a false negative. We continue to indicate with $\alpha_{p}$ the probability of conviction of an innocent firm (false positive) and with $\alpha_{n}\left(\alpha_{p}\right)$ the probability of acquittal of a guilty firm (false negative). We assume that the employee gets the reward $R$ if the firm is convicted. If the firm is acquitted, a second trial takes place.

This second trial is against the whistleblower, accused of fabricating false information and, as with the first trial, may lead to two types of error: a false positive with probability $\beta_{p}$, the probability that an innocent whistleblower is convicted; and false negative with probability $\beta_{n}\left(\beta_{p}\right)$, the probability of acquittal of a whistleblower who filed a false claim fabricating information. If the employee is convicted in this second trial, he faces a sanction denoted with $f$. Also for the second trial we assume that $\beta_{n}^{\prime}\left(\beta_{p}\right)<0$ and $\beta_{i} \in[0, \bar{\beta}]$ with $\bar{\beta}<\frac{1}{2}$ and $i=p, n$. Moreover, we assume that $\alpha_{p}$ and $\beta_{p}$ are independent. ${ }^{13}$

We consider the more general case in which the firm can retaliate against the employee imposing a harm $P$. The case with no retaliation can be obtained by simply setting $P=0$. As mentioned before, the parameter $P$ can also be interpreted as the (inverse of) the protection that the program is able to guarantee to employees that are willing to cooperate with the enforcers. We can follow the same steps as in the two previous sections to identify the conditions that would induce the employee to file a case. If the firm acts illegally, the employee blows the whistle if

$$
u_{2 I}=\left(1-\alpha_{n}\left(\alpha_{p}\right)\right) R-\alpha_{n}\left(\alpha_{p}\right) \beta_{p} f-P>0 \Leftrightarrow S_{I} \equiv \frac{\left(1-\alpha_{n}\left(\alpha_{p}\right)\right)}{\alpha_{n}\left(\alpha_{p}\right)}>\frac{\beta_{p} f+P}{R-P} \equiv G_{I},
$$

whereas he files a case when the firm acts legally if

$$
u_{2 L}=\alpha_{p} R-\left(1-\alpha_{p}\right)\left(1-\beta_{n}\left(\beta_{p}\right)\right) f-P>0 \Leftrightarrow S_{L} \equiv \frac{\alpha_{p}}{1-\alpha_{p}}>\frac{\left(1-\beta_{n}\left(\beta_{p}\right)\right) f+P}{R-P} \equiv G_{L},
$$

where $u_{2 I}$ and $u_{2 L}$ are the employee's expected utility in each subgame that now includes two trials. We have to note that, given the assumptions on $\beta_{i}, G_{L}>G_{I}$. Hence, again there are three possible cases. First, the employee always files a case if $S_{L}>G_{L}$. Note that this condition implies that $S_{I}>G_{I}$. In the second case, the employee never files a case; this occurs if $S_{I} \leqslant G_{I}$, which implies $S_{L}<G_{L}$. Finally,

\footnotetext{
13 Note that this assumption does not imply that the probability of conviction of a whistleblower is independent of the outcome of the first trial. On the contrary, we assume that a trial against the whistleblower occurs only if the firm is acquitted in the first trial. Hence, the probability of conviction of the whistleblower if the firm is acquitted is trivially higher than the probability of conviction of the whistleblower if the firm is convicted. At the end of this section we briefly discuss the possibility that a correlation between the accuracy of the two trials exists.
} 
the employee blows the whistle only against a firm that acted illegally if $S_{I}>G_{I}$ and $S_{L} \leqslant G_{L}$

These conditions are summarized in the following proposition.

Proposition 2 The employee always blows the whistle if $S_{L}>G_{L}$ and the crime rate is

$$
\operatorname{Pr}[\pi \geqslant \underline{\pi}]=1-H\left(F\left(1-\alpha_{n}\left(\alpha_{p}\right)-\alpha_{p}\right)\right),
$$

which is decreasing in the firm's sanction $F$ and in the probability of conviction of an innocent firm $\alpha_{p}$ whenever $\alpha_{n}^{\prime}\left(\alpha_{p}\right)<-1 .^{14}$

The employee blows the whistle only when the firm misbehaves if $S_{I}>G_{I}$ and $S_{L} \leqslant G_{L}$ and the crime rate is

$$
\operatorname{Pr}[\pi \geqslant \bar{\pi}]=1-H\left(F\left(1-\alpha_{n}\left(\alpha_{p}\right)\right)\right),
$$

which is decreasing in the firm's sanction $F$ and in the probability of conviction of an innocent firm $\alpha_{p}$.

Finally, the employee never blows the whistle and the crime rate is 1 if $S_{I} \leqslant G_{I}$.

Hence, the program is effective if and only if $S_{I}>G_{I}$ and $S_{L} \leqslant G_{L}$.

Of course, proposition 2 is a generalization of proposition 1 . Hence, we can make some final remarks on the basis of the results described in this proposition. First, we have to note that the simple sufficient conditions for an effective program discussed in the previous section are no longer valid. However, in this more general case we can exploit the fact that $S_{I}>1>S_{L}$ to identify a similar sufficient condition. Indeed, the whistleblower program induces an optimal behavior by the employee if $G_{I} \leqslant 1$ and $G_{L} \geqslant 1$. Solving the first inequality, we obtain $R \geqslant 2 P+\beta_{p} f$, whereas the second inequality is satisfied if and only if $R \leqslant 2 P+\left(1-\beta_{n}\left(\beta_{p}\right)\right) f$. Hence, the sufficient condition to obtain the desired behavior from the employee is:

$$
2 P+\left(1-\beta_{n}\left(\beta_{p}\right)\right) f \geqslant R \geqslant 2 P+\beta_{p} f .
$$

A whistleblower program can be described by the following policy parameters $\left(R, f, \alpha_{p}, \beta_{p}, P\right)$ which identify the available policy instruments: (1) the reward offered to the whistleblower that helps to uncover an illegal corporate act; (2) the sanction imposed on the whistleblower who fabricates information; (3) the accuracy of the judiciary in deciding on the allegations made against either the firm or the whistleblower; (4) the standard of proof that is required in the two trials to convict either the firm or the whistleblower; (5) the level of protection granted to whistleblowers

14 Again when $\alpha_{n}^{\prime}\left(\alpha_{p}\right) \geqslant-1$, increasing false positives will increase the crime rate. 
against possible retaliations by firms. We can now describe how the various policy instruments affect the effectiveness of the program, as defined in this paper.

Let us start with their impact on $S_{I}$ and $S_{L}$. These odds depend only on $\alpha_{p}$ and $\alpha_{n}$. Therefore, as already said in the previous section, the only relevant policy instruments are the accuracy of the legal system and the standard of proof. Investments made to improve the accuracy of the system may decrease both $\alpha_{p}$ and $\alpha_{n}$. This will make $S_{I}$ and $S_{L}$ move apart ( $S_{I}$ increases and $S_{L}$ decreases), increasing the probability that the whistleblower program is effective. As discussed in the previous section, such an investment has a particularly strong impact if it lowers the probability of false negatives in the first trial. In contrast, increasing the standards of proof that have to be met to convict a firm will decrease $\alpha_{p}$ and increase $\alpha_{n}$. This choice would determine a lower value for both $S_{I}$ and $S_{L}$, making it less likely that the employee files a case.

Moving to $G_{I}$ and $G_{L}$, we note that all the policy instruments are relevant. Their impact on the effectiveness of the program is described in the following table. The first column identifies the policy choices concerning the elements that describe the whistleblower program in our model. The second column describes the impact of these choices on $G_{I}$ and $G_{L}$ and the third column highlights whether some specific conditions must hold to have the impact defined in the second column. In reading the table, one has to bear in mind that a policy choice improves the effectiveness of the program if, ceteris paribus, it decreases $G_{I}$ and/or increases $G_{L}$. Hence, policymakers should be aware that interventions that have an impact on $G_{I}$ and $G_{L}$ of the same sign must be fine-tuned to improve the program.

\begin{tabular}{|c|c|c|}
\hline Policychoice & Impacton $G_{I}$ and $G_{L}$ & Conditions \\
\hline Increase $R$ & Both decrease & always \\
\hline Increase $f$ & Both increase & always \\
\hline $\begin{array}{c}\text { Improve accuracy } \\
\left(\text { decrease } \beta_{p} \text { and/or } \beta_{n} \text { ) }\right.\end{array}$ & $\begin{array}{l}G_{I} \text { decreases } \\
G_{L} \text { increases }\end{array}$ & $R>P$ \\
\hline $\begin{array}{l}\text { Increase standard of proof } \\
\text { (decrease } \beta_{p} \text { and increase } \beta_{n} \text { ) }\end{array}$ & Both decrease & always \\
\hline $\begin{array}{c}\text { Improve protection } \\
(\text { decrease } P)\end{array}$ & Both decrease & always \\
\hline
\end{tabular}

The results reported in the table show that, in general, the various policy instruments must be handled with care as they might lead to a policy that is either too generous to the potential whistleblower or not generous enough. The only policy instrument that has an unambiguous impact on the incentives of the whistleblower is improving the accuracy of the judiciary, which makes it more likely that the employee blows the whistle only when the firm misbehaves. However, this is true only if the program provides a reward and some form of protection against possible retaliations such that the net payoff a successful whistleblower receives is positive.

Now, we may wonder whether, as discussed before for the trial against the firm, also in the trial against the alleged mendacious whistleblower, this policy is particularly effective if it reduces the probability of false negatives. A simple inspection of the definition of $G_{I}$ and $G_{L}$ reveals that this is not the case. Indeed, both $G_{I}$ and $G_{L}$ 
are linear functions of $\beta_{p}$ and $\beta_{n}$ and the absolute value of their slope is the same (i.e. $\frac{f}{R-P}$ ). Hence, the marginal impact of investments that improve the accuracy of the courts is the same independently of whether they decrease the probability of false negatives or the probability of false positives.

Note also that changing the different policy instruments listed above entails different social costs. Increasing the accuracy of the judiciary, in particular, is the most direct way to improve the effectiveness of whistleblower rewards (and of the legal system in general), but as many countries have experienced, it is difficult, and requires the investment of substantial real resources. Increasing possible non-monetary sanctions for fraudulent whistleblowers (jail), if present, will also entail investing real resources and additional social costs. Instead, monetary fines and rewards are welfare neutral transfers, and their change does not require real resources. Rewards are typically self-financing, paid as a fraction of the fines and recoveries they generate (so they do not even bring about the distortion from taxation typical of public funds). Similarly, changing the standard of proof in these court cases does not require consuming real resources. Therefore, there is an 'efficiency ranking' in terms of which policy tools to use. First monetary fines, rewards and standards of proofs should be optimized. Only after doing this, if not sufficient, other steps should be taken. However, our analysis shows that even if fines, rewards and standards of proofs are the most efficient instruments their effectiveness is not straightforward and that, if not properly designed, they can generate undesirable outcomes.

Remark In the previous analysis we made the simplifying assumption that the probability of conviction of an innocent firm is independent of the probability of conviction of an innocent whistleblower. However, it is possible that mendacious employees will be more likely to be convicted for fabricating false evidence when courts are more able to avoid false positives in the first trial. This means that $\left(1-\beta_{n}\right)$ is positively correlated with $\left(1-\alpha_{p}\right)$, which in turn implies that $\alpha_{p}$ and $\beta_{n}$ are also positively correlated. If this is the case, the results summarized in the previous table still hold but with an interesting twist. Indeed, changing the standard of proof or the accuracy of the first trial has spillover effects on the second one. Specifically, an investment to improve the accuracy of the first trial by decreasing (both $\alpha_{p}$ and) $\alpha_{n}$ will also affect the second trial by decreasing the probability of acquittal of a whistleblower who filed a false claim, i.e., decreasing $\beta_{n}$ (a positive spillover). Similarly, increasing the standards of proof that have to be met to convict a firm will decrease $\alpha_{p}$ (and increase $\alpha_{n}$ ) affecting also the second trial through an increase in $\beta_{n}$ (a negative spillover). In other words, a positive correlation between errors in the two trials would confirm our main insight that the only policy instrument that has an unambiguously positive impact on incentives is improving the accuracy of the judiciary. 


\section{Conclusion}

Financial incentives for corporate whistleblowers are at the center of a heated debate, as US enforcement agencies have been increasingly reliant on them, while their European counterparts appear wary of introducing them. One argument that is often raised by opponents of these incentives is that they will lead to an increase in fraudulent reports based on false or fabricated information that, in the end, will reduce the effectiveness of enforcement. Fraudulent claims, however, do not seem to have been a major problem for at least some of the US agencies. One plausible explanation is that, in a sufficiently accurate legal system, fraudulent claims based on false or fabricated information have a sizable probability of failing, possibly also because the standard of proof is raised when a whistleblower expects a reward; and the whistleblowers that brought the claims can then be taken to trial for perjury or defamation. To shed light on this hypothesis, we present a model of the interaction between rewards for whistleblowers, sanctions for maliciously reporting fabricated information, judicial errors, and standards of proof in two court cases - one based on a whistleblower's allegations, and a subsequent one against the whistleblower for possibly false accusations. We use the model to show that an appropriate balance between the reward offered to successful whistleblowers, the sanctions against whistleblowers convicted for fabricating information, and the courts' standards of proof is essential for whistleblower policies to succeed.

When the risk of retaliation against whistleblowers is severe, higher rewards are needed for the program to be effective, and even more severe sanctions against dishonest whistleblowers become necessary. An implication of this is that the precision of the legal system must be sufficiently high for these programs to be viable at all. This suggests that these schemes should not be introduced in weak institutional environments, where protection from retaliation is typically less effective and the precision of the legal system is typically low.

Acknowledgments We would like to thank the Editor, Alain Marciano, two anonymous referees and Bill Kovacic, Giuliana Palumbo, Salvatore Piccolo, Patrick Rey for many useful discussions related to this project. Spagnolo is grateful to the Wallander and Hedelius foundation for financial support (HandelsbankenP2013-0162)

Funding Open access funding provided by Università degli Studi di Napoli Federico II within the CRUICARE Agreement.

Open Access This article is licensed under a Creative Commons Attribution 4.0 International License, which permits use, sharing, adaptation, distribution and reproduction in any medium or format, as long as you give appropriate credit to the original author(s) and the source, provide a link to the Creative Commons licence, and indicate if changes were made. The images or other third party material in this article are included in the article's Creative Commons licence, unless indicated otherwise in a credit line to the material. If material is not included in the article's Creative Commons licence and your intended use is not permitted by statutory regulation or exceeds the permitted use, you will need to obtain permission directly from the copyright holder. To view a copy of this licence, visit http://creativecommons.org/licen ses/by/4.0/. 


\section{References}

Abbink, K., \& Wu, K. (2017). Reward self-reporting to deter corruption: An experiment on mitigating collusive bribery. Journal of Economic Behavior \& Organization, 133, 256-272.

Amir, E., Lazar, A., \& Levi, S. (2018). The Deterrent Effect of Whistleblowing on Tax Collections. European Accounting Review, 75(5), 939-954.

Apesteguia, J., Dufwenberg, M., \& Selten, R. (2007). Blowing the whistle. Economic Theory, 31(1), $143-166$.

Aubert, C., Kovacic, W., \& Rey, P. (2006). The impact of leniency and whistleblowing programs on cartels. International Journal of Industrial Organization, 24, 1241-1266.

Bank of England-Prudential Regulations Authority \& Financial Conduct Authority (BoE-PRA and FCA), (2014). Financial Incentives for Whistleblowers. Available for download in September 2016 until (at least) June 2017 at https://www.fca.org.uk/news/financial-incentives-for-whistleblo wers.

Bigoni, M., Le Coq, C., Fridolfsson, S., \& Spagnolo, G. (2012). Fines, leniency and rewards in antitrust. RAND Journal of Economics, 43(2), 368-390.

Breuer, L. (2013). Tax compliance and whistleblowing-the role of incentives. The Bonn Journal of Economics, 2(2), 7-44.

Butler, J., Serra, D., \& Spagnolo, G. (2017). Motivating Whistleblowers. Working Paper, Southern Methodist University.

DLA Piper (2015). Wistleblowing laws: An employer's guide to global compliance. 2nd edn. Available at https://www.dlapiper.com/ /media/Files/Insights/Publications/2015/06/Whistleblowing Law_Report_2015.pdf.

Dyck, A., Morse, A., \& Zingales, L. (2010). Who Blows the Whistle on Corporate Fraud? The Journal of Finance, 65, 2213-53.

Engstrom, D. F. (2016). Bounty Regimes. In J. Arlen (Ed.), Research handbook on corporate criminal enforcement and financial misdealing. Cheltenham: Edward Elgar Press.

Felli, L., \& Hortala-Vallve, R. (2016). Collusion, blackmail and whistle-blowing. Quarterly Journal of Political Science, 11(3), 279-312.

Friebel, G., \& Guriev, S. (2012). Whistle-blowing and incentives in firms. Journal of Economics \& Management Strategy, 21(4), 1007-1027.

GAO-11-619 (2011). U.S. Gov't Accountability Office Report 11-619, Criminal Cartel Enforcement: Stakeholder Views on Impact of 2004 Antitrust Reform Are Mixed, but Support Whistleblower Protection. Available at http://www.gao.gov/new.items/d11619.pdf.

Givati, Y. (2016). A theory of whistleblower rewards. Journal of Legal Studies, 45, 43-72.

Howse, R., \& Daniels, R. J. (1995). Rewarding Whistleblowers: The Costs and Benefits of an Incentive-Based Compliance Strategy. Corporate Decision-Making in Canada pp. 525-549.

Heyes, A., \& Kapur, S. (2009). An economic model of whistle-blower policy. Journal of Law, Economics, \& Organization, 25(1), 157-182.

Kaplow, L. (2011a). On the optimal burden of proof. Journal of Political Economy, 119, 1104-1140.

Kaplow, L. (2011b). Optimal proof burdens, deterrence, and the chilling of desirable behavior. American Economic Review: Papers and Proceedings, 101, 277-280.

Kaplow, L. (2012). Burden of Proof. Yale Law Journal, 121, 738-859.

Kovacic, W. E. (2000). Private monitoring and antitrust enforcement: Paying informants to reveal cartels. George Washington Law Review, 69, 776.

Leder-Luis, J. (2020). Whistleblowers, private enforcement, and medicare fraud. Working paper, Available at: https://sites.bu.edu/jetson/files/2020/07/False-Claims-Act-Paper.pdf

Mechtenberg, L., Muehlheusser, G. \& Roider, A. (2017). Whistle-blower protection: Theory and experimental evidence. CEPR Discussion Paper No. 11898.

Miceli, M. P., \& Near, J. P. (1992). Blowing the Whistle: The Organizational and Legal Implications for Companies and Employees. Lanham: Lexington Books.

Miceli, M. P., Near, J. P., \& Dworkin, T. M. (2008). Whistle-blowing in organizations. New York: Routledge.

Nyreröd, T., \& Spagnolo, G. (2021). Myths and numbers on whistleblower rewards. Regulation and Governance, 15(1), 82-97.

Piccolo, S., \& Immordino, G. (2017). Organized crime, insider information and optimal leniency. Economic Journal, 127, 2504-2524. 
Raleigh, J. (2020). The Deterrent Effect of Whistleblowing on Insider Trading, working paper. Available at: https://papers.ssrn.com/sol3/papers.cfm?abstract_id=3672026

Rose, A. M. (2014). Better bounty hunting: How the SEC's new whistleblower program changes the secretes fraud class action debate. Northwestern University Law Review, 108(4), 1235-1302.

Schmolke, K. U., \& Utikal, V. (2016) Whistleblowing: Incentives and Situational Determinants. FAU - Discussion Papers in Economics, No. 09/2016, Available at SSRN: https://ssrn.com/abstract= 2820475 or https://doi.org/10.2139/ssrn.2820475.

Spagnolo, G. (2004). Divide et Impera: Optimal Leniency Programmes. CEPR Discussion Paper nr 4840.

Stikeleather, B. (2016). When do employers benefit from offering workers a financial reward for reporting internal misconduct? Accounting, Organizations and Society, 52, 1-14.

Transparency International. (2013). Whistleblowing in Europe, Legal Protections for Whistleblowers in the EU.

Wiedman, C., \& Zhu C. (2018). Do the SEC Whistleblower Provisions of Dodd-Frank Deter Aggressive Financial Reporting? Canadian Academic Accounting Association (CAAA) Annual Conference, Available at: https://ssrn.com/abstract=3105521.

Zingales, L. (2004). Want to Stop Corporate Fraud? Pay Off Those Whistle-Blowers. The Washington Post, January 18.

Publisher's Note Springer Nature remains neutral with regard to jurisdictional claims in published maps and institutional affiliations. 